\title{
Efficient Protection of Alcohols with Carboxylic Acids Using a Variety of Heteropolyoxometallates as Catalysts, Studying Effective Reaction Parameters
}

\author{
Reza Tayebee` and Fatemeh Cheravi \\ Deparment of Chemistry. Sabzevar Tarbiat Moallem University, Sabzevar 397. Iran. 'E-mail: ravebeeiâsm acth ir \\ Received July 7, 2009, Accepted September 14, 2009
}

\begin{abstract}
Esterification is an important class of reactions in the preparation of perfumery and flavor chemicals, wherein homogeneous, solid acidic, and superacidic catalysts are normally used. Now, an efficient and selective protocol for protection of various functionalized alcohols employing carboxylic acids as protecting agents is realized through the catalytic mediation of simple heteropolyosometallates. In this methodology, water is the only by-product and notably the aspect of effluent treatments does not arise. The advantages include the operational simplicity, recycle ability of the catalyst and mild reaction conditions. The present catalytic sy stem may be a potential candidate not only for laboratory practice but also for conmercial applications and offers an envirommentally safer altemative to the existing processes.
\end{abstract}

Key Words: Acetylation. Heteropolyoxometallate. Catalytic. Alcohol. Formylation

\section{Introduction}

The protection of hydroxyl functional groups is an important and widely used transformation and is often necessary during the course of various organic synthesis sequences. in particular in the construction of polyfunctional molecules such as nucleosides, carbohydrates, steroids. natural products, and dnigs. A number of reagents coupled with different cataly sts have been put forth for the protection of alcohols. Protection of alcohols is usually performed employing acid anhydrides or acyl chlorides in the presence of stoichiometric amounts of protonic and Lewis acids. such as $p$-toluenesulfonic acid. ${ }^{1}$ scandium trifluromethanesulfonate. ${ }^{2}$ trimethylsilyl triflouromethanesulfonate, ${ }^{3}$ zinc chloride, ${ }^{+}$and cobalt chloride. above options employing acetic anhydride as acetylating agent and soluble acids as reagents or catalysts presents achieve less than $50 \%$ atom economy in the consumption of acetic anhydride by utilizing only the acetyl group. Moreover, acid halides and acid anhydrides are usually employed as the acetylating agents in the presence of an acid or base catalyst such as $\mathrm{H}_{2} \mathrm{SO}_{4}{ }^{6}{ }^{6} \mathrm{PTSA}$. Shro's catalyst, ${ }^{8}$ distannoxane cataly st ${ }^{9}$ and lipase. ${ }^{10}$ Most of the above procedures can be applied for the protection of various acid/base sensitive substrates. However. limitations in terms of reagent availability prolonged reaction times. formation of unwanted side products. and need for halogenated solvents are of drawbacks of these common methods. Considering the importance of environmental awareness in chemical technology. it is important to minimize the prevalence of undesirable hazardous chemical substances that are dangerous to human health and the environment.

Heteropolyoxometallates of the Keggin series have been proven to be good catalysts in many homogenous organic transformations and for the synthesis of fine and specialty chemicals. ${ }^{11-1+}$ Due to their acidic nature. redox properties. catalytic activity, selectivity. thermal resistance, and reusability heteropoly compounds are useful and versatile catalysts in a number of transformations. ${ }^{15-16}$ These interesting compounds generally exhibit higher catalytic activities than con- ventional catalysts. such as mineral acids. ion-exchange resins. zeolites, etc in both heterogeneous and homogeneous systems. " Furthermore. heteropoly catalysis lacks side reactions, such as sulfonation. chlorination. etc. that frequently occur with mineral acids. Most of usual Keggin-type heteropolyoxometallates are soluble in water and polar organic solvents. such as lower alcohols and carboxylic acids, but insoluble in hydrocarbons. This provides an opportunity for the easy recovery of catalysts from liquid-phase reaction sy stems without neutralization. simply by precipitating with a hydrocarbon solvent. ${ }^{11}$

In continuation of our ongoing research program on using heteropolypolyoxometallates in organic synthesis. ${ }^{1 ?-2 ?}$ herein. we wish to report a simple. efficient, selective, and general method for the protection of some alcohols by the mediation of some heteropoly compounds at room temperature or under reflux conditions. The reactions were carried out in good yields within quite short reaction times.

\section{Results and Discussion}

Functional group protection is the heart and soul of multifunctional and nulti step syntheses of target molecules. The protection of alcohol moieties represents one of the most ubiquitous steps in chemistry. Organic esters are a very important class of chemicals having applications in phannaceuticals. Since. acetyl is the most common group in view of easy introduction being stable under acidic conditions, and being easily removable by mild alkaline hydrolysis. the protection of alcohol functional groups is usually achieved through acetylation and obviously different approaches have been employed on both laboratory and commercial scales to prepare esters.

As mentioned in the introduction. research has been directed to overcome the drawbacks of conventional methods and insurnnountable problems in the recovery of the catalysts and by-products and there is a need to develop a reusable and economic solid acid cataly st for acetylation using carboxylic acids as acetylating agents to achieve ligh atom econony 
Table 1. Protection of some Alcohols with Acetic Acid Catalyzed by $\mathrm{H}_{3} \mathrm{PW}_{12} \mathrm{O}_{4 \mid 1 .}{ }^{a}$

\begin{tabular}{|c|c|c|c|c|c|c|}
\hline & & $\mathrm{H}_{3} \mathrm{C}-$ & $0.34 \%$ & $\frac{\mathrm{H}_{3} \mathrm{PW}_{12} \mathrm{O}_{40}}{0 \mathrm{C}^{6}}$ & $\mathrm{R}^{\mathrm{O}}$ & \\
\hline Entry & Alcohol & $\begin{array}{c}\text { Short time } \\
\text { Conv.\% (min.) }\end{array}$ & $\begin{array}{c}\text { Long time } \\
\text { Conv } \%(\mathrm{~min} .)\end{array}$ & $\begin{array}{l}\text { Selectivity } \\
(\%)\end{array}$ & $\begin{array}{l}\mathrm{TON}^{b} \text { short time } \\
\text { (long time) }\end{array}$ & $\begin{array}{l}\text { TOF }^{c} \text { short time } \\
\text { (long time) }\end{array}$ \\
\hline 1 & & $45(5)$ & $90(15)$ & 100 & $132(264)$ & $1594(1058)$ \\
\hline 2 & & $25(5)$ & $90(25)$ & 100 & $73.5(264)$ & $885(635)$ \\
\hline 3 & & $5(5)$ & $75(50)$ & 100 & $14.7(220)$ & $177(264)$ \\
\hline 4 & $>\mathrm{C}-\mathrm{OH}$ & $75(5)$ & $86(15)$ & $>98$ & $220(252)$ & $2657(1011)$ \\
\hline $5^{3}$ & & $24(120)$ & $70(300)$ & 100 & $73.5(205)$ & $35(41)$ \\
\hline 6 & & $7(5)$ & $35(60)$ & 100 & $20.5(103)$ & $248(103)$ \\
\hline 7 & & $7(15)$ & $26(60)$ & $>97$ & $20.5(76.4)$ & $82(76)$ \\
\hline 8 & & $20(5)$ & $90(35)$ & 100 & $58.8(264)$ & $708(453)$ \\
\hline 9 & & $50(5)$ & $90(20)$ & 98 & $147(264)$ & $1771(794)$ \\
\hline 10 & & --- & $3(180)$ & 100 & $\cdots(8.82)$ & $\cdots(3)$ \\
\hline
\end{tabular}

${ }^{a}$ Cataly st $(0.03+\mathrm{mmol})$ was dissolved in a solution of acetic acid $(50 \mathrm{mmol})$ and alcohol $(10 \mathrm{mmol})$ followed by heating the reaction mixture to 70$)^{\circ} \mathrm{C}$ under vigorous stiming. All acetylated products were jnown compounds and were identified by means of IR and H-NMR spectroscopy andior comparison of their b.p. or m.p. with authentic samples. ${ }^{+2 .}{ }^{6}$ Turnover number (TON) is the number of moles of product per mole of catalyst. "Turnoter frequency (TOF) was calculated by the expression [product] [ catalyst] · time $\left(\mathrm{h}^{-1}{ }^{-1}\right.$. "Benzoic acid was used instead of acetic acid. 
Considering this demand, heteroplyacids have emerged as green catalysts for chemical technology owing to their high catalytic activity in low concentration and being environmentally friendly. Heteroplyacids are yet non-corrosive and work in low concentration. thus avoiding disposal problems.

Initially. 1-phenyl ethanol was chosen for the acetylation reactions (Table 1). The protection reactions were carried out in a glass reactor equipped with a magnetic stirrer. The homogeneous reactions were performed by adding the above alcohol $(10 \mathrm{mmol})$ as a model substrate to a solution of $\mathrm{H}_{3} \mathrm{PW}_{12} \mathrm{O}_{4}(0.034 \mathrm{mmol})$ in acetic acid $(50 \mathrm{mmol})$. At appropriate time intervals. aliquots were taken. diluted ten-fold with dichloromethane and analyzed by GLC. In the presence of $0.3+\mathrm{mol}_{0}$ of $\mathrm{H}_{3} \mathrm{PW}_{12} \mathrm{O}_{4 i}$ as the dissolved heteropoly acid. acetic acid was added to I-phenyl ethanol and progressed up to $90 \%$ with almost complete selectivity at $70^{\circ} \mathrm{C}$ after $15 \mathrm{~min}$. In the absence of cataly st. acetic acid was much less efficient for the conversion of 1-phenyl ethanol and led to $<5 \%$ of product after $60 \mathrm{~min}$. (Table 2 . entry 16).

To evaluate the efficiency of $\mathrm{H}_{3} \mathrm{PW}_{13} \mathrm{O}_{41}$ as catalyst, the general applicability and scope of the method was studied by use of various alcohols. As shown in Table 1, a series of structurally diverse aliphatic and aromatic primary, secondary, tertiary, and benzy lic alcohols underwent smooth acetylation in good yields with acetic acid in the presence of $0.34 \mathrm{~mol} \%$ of $\mathrm{H}_{3} \mathrm{PW}_{12} \mathrm{O}_{4}$. A sterically hindered ${ }^{\mathrm{t}} \mathrm{BuOH}$ yields $86 \%$ of the corresponding acetate after $15 \mathrm{~min}$. (Table 1 , entry 4): whereas. cyclohexanol and menthol as secondary cyclic alcohols showed lower reactivity than other examined alcohols and produced $35 \%$ and $26 \%$ of the corresponding products, respectively. after $60 \mathrm{~min}$. Phenolic hydroxyl group could not be acetylated under the reported condition. Phenol undervent the acetylation slowly in the presence of catalyst and led to $3 \%$ of product after 3 h (Table 1, entry 10). This inertness has been exploited to selective acetylation of alcoholic hydroxyl groups in phenols. Primary and secondary linear alcohols were also acetylated with good yields in this system. 1-Buthanol produced $90 \%$ of conversion after $25 \mathrm{~min}$, whereas. 2-propanol led to $75 \%$ of the acetylated product after $50 \mathrm{~min}$ (Table 1 . entries 2 and 3 ). This means that secondary alcohol. 2-pro- panol. was less reactive than the printary one in the protection protocol. Benzyl alcohol and 4-methoxy-benzyl alcohol were also acetylated in a reasonable time and produced $90 \%$ of conversion after 35 and $20 \mathrm{~min}$, respectively (Table 1, entries 8 and 9).

Our findings showed that $\mathrm{H}_{4} \mathrm{SiW}_{12} \mathrm{O}_{4 \mathrm{i}}$ is capable of cataly zing acetylation of 1 -phenyl ethanol with acetic acid. It led to $86 \%$ of 1 -phenyl ethyl acetate with almost complete selectivity after $15 \mathrm{~min}$. (Table 2 , entry 15 ). The reactivity of other heteropolyanions such as $\mathrm{H}_{4} \mathrm{SiW}_{12} \mathrm{O}_{410} . \mathrm{K}_{4} \mathrm{SiW}_{9} \mathrm{Mo}_{2} \mathrm{O}_{39}$, and $\mathrm{Na}_{3} \mathrm{PW}_{9} \mathrm{Mo}_{3} \mathrm{O}_{4 i}$ were also exanuned (Table 2). Within the examined catalysts. the reactivity pattern $\mathrm{H}_{3} \mathrm{PW}_{12} \mathrm{O}_{410}>\mathrm{H}_{4}$ $\mathrm{SiW}_{1 \_} \mathrm{O}_{4 i}>\mathrm{H}_{3} \mathrm{PMo}_{12} \mathrm{O}_{4 i}>\mathrm{Na}_{3} \mathrm{PW}_{9} \mathrm{Mo}_{3} \mathrm{O}_{4 i}>\mathrm{K}_{4} \mathrm{SiW}_{9} \mathrm{Mo}_{2} \mathrm{O}_{30}$ was observed.

We extended the scope of this procedure by performing the protection reaction of 1-phenyl ethanol in other carboxylic acids (Table 3). The results proved that formic acid is distinctly more reactive than acetic acid, and led to $85 \%$ of conversion after $5 \mathrm{~min}$. (Table 3. entry 19). Acetic acid behaved as well as glacial acetic acid: while propionic acid revealed less reactivity and produced $90 \%$ of the corresponding product after 25 min. (Table 3 , entry 20). Dichloroacetic acid was more effective than other analogues and produced $96 \%$ of acetate after 5 min. (Table 3 , entry 22). Obviously. benzoic acid showed little activity and produced $24 \%$ of the acetylated product after $120 \mathrm{~min}$. (Table 3 . entry 21 ).

Formylation is also a very important process and several cataly sts have been used for this transformation. ${ }^{28}$ Because of the instability of the anhydride and the acid clloride of formic acid, fornylation of alcohols has been achieved using ethyl formate. As previously described ethyl formate is capable of protecting alcohols. such as l-butanol, and led to $85 \%$ of 1-butyl acetate after $10 \mathrm{~min}$. (Table 3 , entry 23 ).

Industrially a variety of applied esterification procedures are commonly catalyzed using mineral liquid acids. Although. the catalytic activity of these homogeneous catalysts is high. they suffer from several drawbacks, such as their corrosive nature. the existence of side reactions. and the fact that the catalyst cannot be easily separated from the reaction mixture. ${ }^{5.32}$ The use of reusable acid catalysts, offer an alterna-

Table 2. Protection of 1-Phenyl Ethanol with Acetic Acid Catalyzed by Various Heteropolyoxometals."

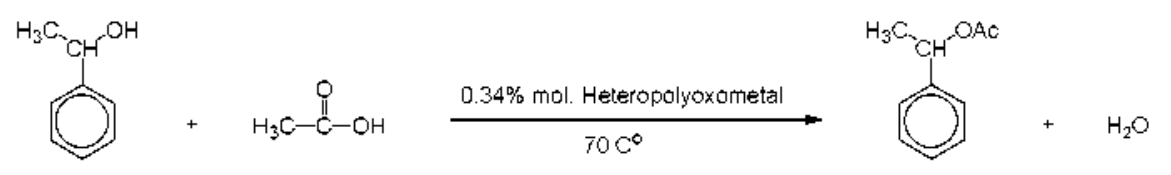

\begin{tabular}{clccccc}
\hline Entry & Catalyst & $\begin{array}{c}\text { Short time } \\
\text { Conv.\%(min.) }\end{array}$ & $\begin{array}{c}\text { Long time } \\
\text { Conv\%(min.) }\end{array}$ & $\begin{array}{c}\text { Selectivity } \\
(\%)\end{array}$ & $\begin{array}{c}\text { TON short time } \\
\text { (long time) }\end{array}$ & $\begin{array}{c}\text { TOF short time } \\
\text { (long ime) }\end{array}$ \\
\hline 11 & $\mathrm{H}_{3} \mathrm{PW}_{12} \mathrm{O}_{40}$ & $45(5)$ & $90(15)$ & $>98$ & $132(264)$ & $1594(1058)$ \\
12 & $\mathrm{H}_{3} \mathrm{PMo}_{12} \mathrm{O}_{40}$ & $30(5)$ & $90(40)$ & $898(264)$ & $1059(397)$ \\
13 & $\mathrm{Na}_{3} \mathrm{PW}_{4} \mathrm{Mo}_{3} \mathrm{O}_{41}$ & $15(5)$ & $80(45)$ & 97 & $44(228)$ & $531(314)$ \\
14 & $\mathrm{~K}_{4} \mathrm{SiW}_{9} \mathrm{Mo}_{2} \mathrm{O}_{39}$ & $1(35)$ & $4(150)$ & 100 & $3(11.7)$ & $50(5)$ \\
15 & $\mathrm{H}_{4} \mathrm{SiW}_{12} \mathrm{O}_{40}$ & $60(5)$ & $86(15)$ & $>98$ & $176(252)$ & $2126(1011)$ \\
16 & Without & $5(60)$ & $20(180)$ & $>98$ & $14.7(58)$ & $14.7(19.6)$ \\
\hline
\end{tabular}

"The reactions were carried out as described below Table 1. 
Table 3. Protection of I-Phenyl Ethanol with some Carboxylic Acids and Ethyl Formate Catalyzed by $\mathrm{H}_{3} \mathrm{PW}_{12} \mathrm{O}_{40}{ }^{\circ}$

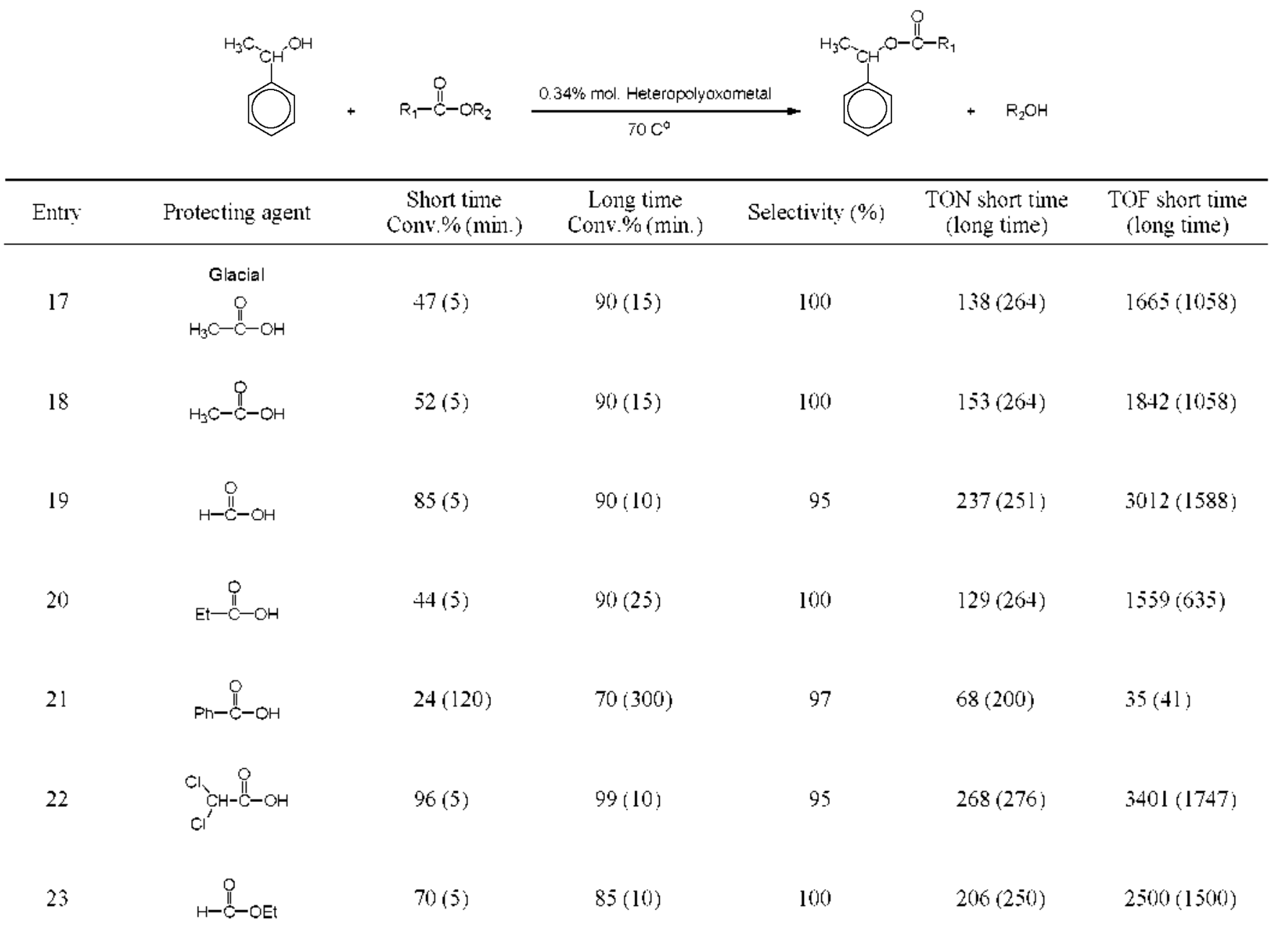

${ }^{2}$ The reactions were carried out as described below Table 1.

tive and have received a lot of attention in the past few years. ${ }^{33-36}$ It is worth mentioning that heteropolyoxometallate catalysts could be used as recrclable catalysts. The acetylation of 1-phenyl ethanol with acetic acid was chosen as a model substrate for studying of catalyst's reuse and stability. After the reaction was worked up. $\mathrm{H}_{3} \mathrm{PW}_{13} \mathrm{O}_{40}$ has been recovered and subsequently used as catalyst in a second esterification reaction to investigate the reusability of catalyst. In the second esterification experiment, the activity of the catalyst was nearly similar to the activity of the fresh compound and no important loss of catalytic activity was observed. After the use of catalyst for five consecutive cycles, the yield of acetylated product produced from the reaction of I-phenyl ethanol with acetic acid was $85 \%$ and after ten times was $80 \%$. Thus it can be concluded that the used heteropolyoxometallates can be regenerated and reused after a simple work up.

The selectivity towards the competitive acetylation of benzylic and secondary alcohols with acetic acid was also investigated. A mixture of equal amounts of benzyl alcohol ( 5 mmol) and cyclohexanol ( $5 \mathrm{mmol}$ ) was conducted to the protection reaction with acetic acid $(50 \mathrm{mmol})$. Findings revealed that benzyl alcohol was more reactive than cyclohexanol. and produced $90 \%$ of product after $45 \mathrm{~min}$ : whereas. the same conversion was achieved for cyclohexanol after 120 nin.

Fig. l describes effect of increasing concentration of $\mathrm{H}_{3}$ $\mathrm{PW}_{12} \mathrm{O}_{41}$ on the efficiency of I-phenyl ethanol protection with acetic acid. According to our findings, this protection sy stem was unsuccessful to acetylate alcohols in the absence of catalyst under the reaction conditions reported here. Enhancing the catalyst concentration to $0.07 \mathrm{~mol} \%$ caused a distinct increase in the conversion of alcohol. Increasing the catalyst concentration from 0.07 to $1 \mathrm{~mol} \%$. led to higher amounts of products in short and long reaction times. Increasing cataly'st concentration more than $1 \mathrm{~mol} \%$, had only a little effect on the conversion $\%$.

The mole ratio of acetic acid : 1 -phenyl ethanol was varied from $1: 1$ to $10: 1$ to assess its effect on the reaction progress (Fig. 2). It was found that conversion of alcohol was increased with enhancing concentration of the carboxylic acid. A large increase in the yield\% was observed for $10: 1$ mole ratio in comparison with $5: 1$ mole ratio after $5 \mathrm{~min}$. However, the corresponding conversions were close to each other after $15 \mathrm{~min}$.

Effect of temperature on the reaction progress was studied by performing the acetylation of 1-phenyl ethanol in acetic 


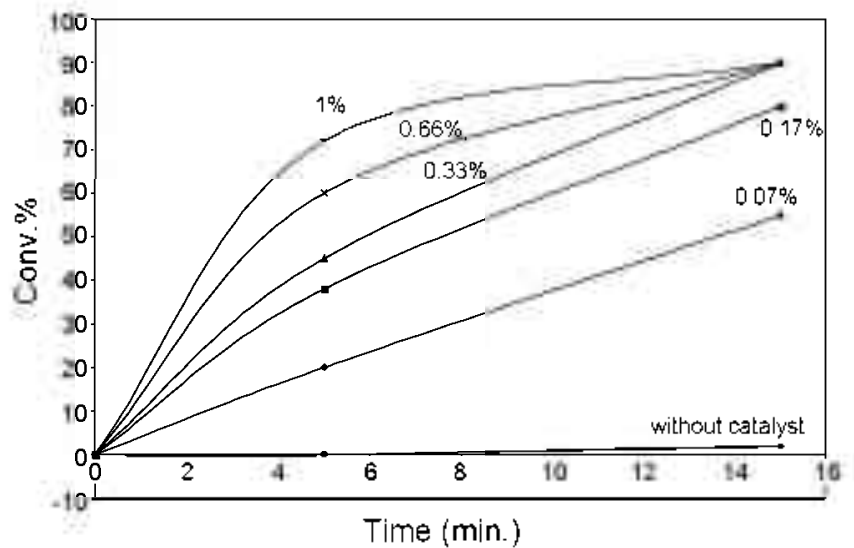

Figure 1. Eftect of Cataly st Concentration ( $\mathrm{mol}_{\%}$ of $\mathrm{H}_{3} \mathrm{PW}_{12} \mathrm{O}_{40}$ ) on the Protection of 1-Phenyl Ethanol with Acetic Acid.

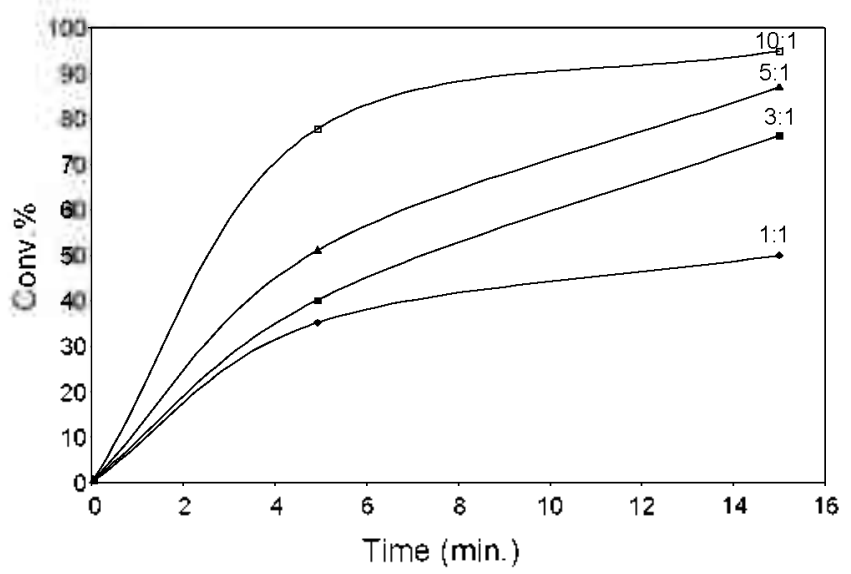

Figure 2. Eftect of Acetic Acid : 1-Phenyl Ethanol Mole Ratio on the Efficiency of the Protection Procedure in the presence of $0.34 \mathrm{~mol} \%$ $\mathrm{H}_{3} \mathrm{PW}_{12} \mathrm{O}_{40}$.

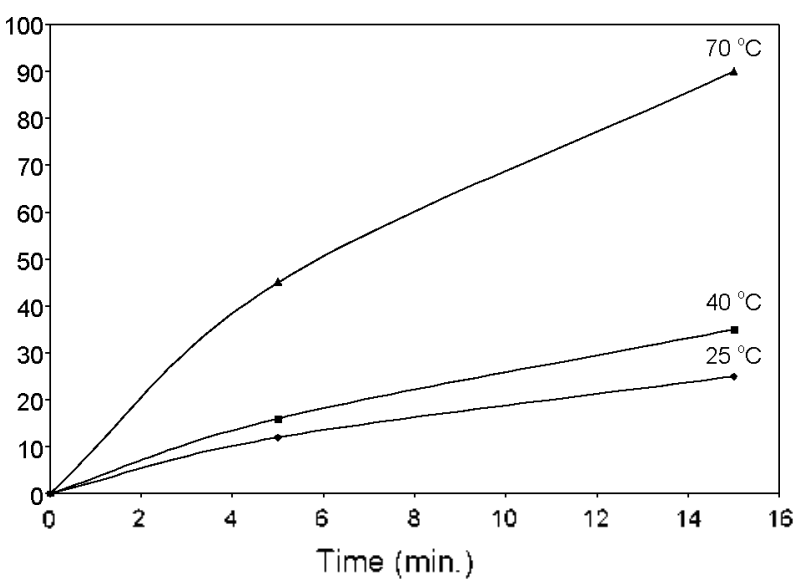

Figure 3. Effect of Raising Temperature on the Extent of 1-Phenyl Ethanol Protection with Acetic Acid Catalyzed by $\mathrm{H}_{2} \mathrm{PW}_{12} \mathrm{O}_{40}$.

acid catalyzed by $\mathrm{H}_{3} \mathrm{PW}_{12} \mathrm{O}_{40}$ at 25,40 and $70^{\circ} \mathrm{C}$ (Fig. 3). The ester y ield \% was increased sharply with enhancing temperature from 25 to $70^{\circ} \mathrm{C}$. It was also interesting that even at elevated temperatures no olefin ether or polymeric products were found in the acetylation of alcohols coaxed with carboxylic acids.

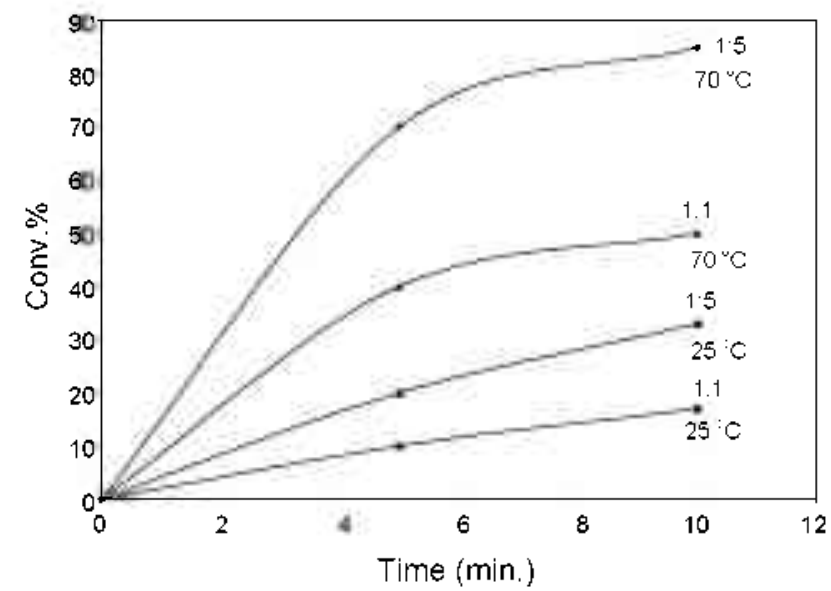

Figure 4. Protection of 1 -Buthanol with Ethyl Fomate ( $1: 1$ and $1: 5$ mole ratio of alcohol : ethyl fonmate) Catalyzed by $\mathrm{H}_{3} \mathrm{PW}_{12} \mathrm{O}_{40}$ at $25^{\circ}$ and $70^{\circ} \mathrm{C}$.

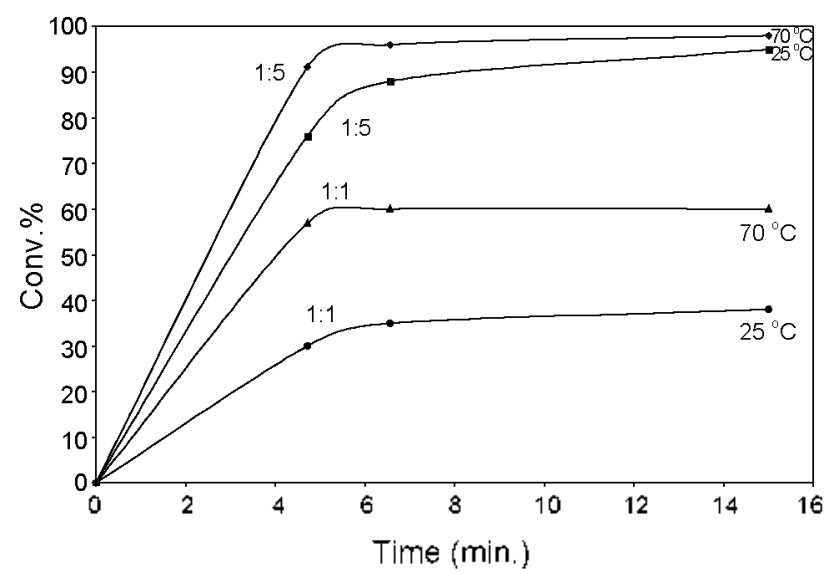

Figure 5. Protection of 1 -Buthanol with Formic Acid ( $1: 1$ and $1: 5$ mole ratio of alcohol : formic acid) Catalyzed by $\mathrm{H}_{3} \mathrm{PW}_{12} \mathrm{O}_{40}$ at 25 and $70^{\circ} \mathrm{C}$.

These results indicate that the process of acetylation affords excellent possible atom economy when accounted with respect to substrate. product. acetylating reagent and the catalyst.

Finally, to obtain a deeper insight on the role of kind and concentration of the protecting agent on the efficacy of the protocol. formylations of 1-buthanol with ethyl formate and formic acid in the presence of $\mathrm{H}_{3} \mathrm{PW}_{12} \mathrm{O}_{40}$ were compared at 25 and $70^{\circ} \mathrm{C}$ (Figs. 4 and 5). Results revealed that formic acid was more effective protecting agent than ethyl formate in short reaction time ( $<5$ min.). Aside from temperature. the first led to $>75 \%$ of conversion with $1: 5$ mole ratio of alcohol : ethyl formate after $5 \mathrm{~min}$. Moreover, the conversion of alcohol was strongly depended on the mol\% of the protecting agent in both temperatures. Effect of increasing mol\% of the protecting agent was more pronounced for formic acid than for ethyl formate. It seems that in the case of formic acid. enhancing $\mathrm{mol} \%$ of acid was more effective than elevation of temperature on the reaction progress.

\section{Experimental Section}

General. All products were characterized by comparison of 
their spectral and physical data with those of authentic samples. Silica gel 60 (70 - 230 mesh) was used for column chromatography. Progress of the reactions was monitored by gas chromatography on a Shimadzu GC-17A instrument equipped with a flame ionization detector using $25 \mathrm{~m} \times 0.25 \mathrm{~mm} \mathrm{CPB}$ 5 - 20 capillary columns. ${ }^{\mathrm{H}} \mathrm{NMR}$ spectra was recorded in $\mathrm{CHCl}_{3}$ as solvent on a spectrometer using TMS as an internal standard. UV-Vis spectra were recorded on a UV-2550 (Shimadzu) spectrophotometer. Infrared spectra were nun on a 8700 Shimadzu Fourier Transform spectrophotometer. The catalysts were prepared and characterized according to literature procedures. ${ }^{3-4}$

Typical Experimental Procedure for Acetylation of Alcohols with Acetic Acid Catalyzed by Hetenopolyoxometallates. In a round-bottom flask ( $10 \mathrm{~mL}$ ) equipped with a magnetic stirrer. the catalyst $(0.034 \mathrm{mmol})$ was dissolved in acetic acid $(50$ mmol). Then the corresponding alcohol ( $10 \mathrm{mmol}$ ) was added to the stirred solution and the reaction mixture was heated to $70^{\circ} \mathrm{C}$ for the required time. The reaction progress was monitored by GLC. After completion of the reaction. acetic acid was removed under reduced pressure and $20 \mathrm{~mL}$ of ether were added. The reaction mixture was washed with $5 \% \mathrm{NaHCO}_{3}$ solution, then with $\mathrm{H}_{2} \mathrm{O}$. and dried with $\mathrm{MgSO}_{4}$. Exaporation of the solvent followed by silica-gel chromatography provided the pure acetate.

\section{Conclusion}

In conclusion. we have demonstrated an efficient and selective protection procedure for various alcohols using some carboxy lic acids and esters as protecting agents in the presence of catalytic amounts of heteropolyoxometallates to achieve optimum yields. In this methodology, notably the aspect of effluent treatments does not arise as water is the only by-product. The advantages include the operational simplicity. recycle ability of the catalyst. and mild reaction conditions. The present catalytic system may be a potential candidate not only for laboratory practice but also for commercial applications and offers an environmentally safer alternative to the existing processes.

Aclonowledgments. The financial support from the research council of Sabzevar Tarbiat Moallem University is greatly appreciated.

\section{References}

1. Cope, A. C.: Herrick, E. C. Org. Smth 1963, 4, 304

2. Ishihara, K.; Kubota, M.; Kurihara, H.; Yamamoto, H. J. Org. Chen. 1996, 61, 4560 .

3. Procopiou, P. A.; Baugh, S. P. D.; Flank, S. S.; Inglis, G. A. Chem. Commum. 1996, 2625
4. Baker, R. H.; Bordwell, F. G. Org. Smth. Coll 1955, 3, 141.

5. Iqbal, I.; Srivastva, R. R. J. Org. Chem. 1992, 57,2001.

6. Sarel, S.; Newman, M. S. J.4m. Chem. Soc. 1956, 78, 5416.

7. Hossain, N.; Magnussan, G. Tetrohedron Lett. 1999, t0, 2217.

8. Matute, B. M.; Backvall, J.-E. J. Org. Chem. 2004, 69, 9191.

9. Orita, A.: Ito, T.; Yasui, Y.: Otera, J. Syn. Lett. 1999, 1927.

10. Adam, W.; Moller, C. R. S.: Schmid, K. S. J. Org. Chem 2001, 66,7365 , and references therein.

11. Kozhewnikov, I. V. Chem. Rev, 1998, 98, 171

12. Okuhara, T: Mizuno, N.: Misono, M. Adv Catal. 1996, $11,113$.

13. Jansen, R. J. I; van Veldhuizen, H. M.: Schwegler, M. A.; van Bekkum, H. Red. Trav Chimt Pays-Bas. 1994, 113, 115.

14. Misono, M:- Nojiri, N. Appl. Catal. 1990, 64, 1 .

15. Tiofeeva, M. N.; Dimidov, A. V.: Kozhevnikov, I. V. J. Mol. Catal. 1979, 179,21.

16. Drago, R. S.: Dias, T. A.; Maier, T. J. Am Chem Soc. 1997, 119, 7702 .

17. Alizadeh, M. H.; Tayebee, R. J. Braz. Chemt. Soc. 2005, 16, 108.

18. Alizadeh, M. H.: Razavi, H.: Bamoharam, F. F. J. hol Catal. 1. Chem 2003, 200, 105 .

19. Tayebee, R. J. Koreon Chent. Soc 2008, 52(1), 23.

20. Alizadeh, M. H.; Hamalker, S. P.; Teanin, Y.; Pope, M. T. J.Am. Chem. Soc. 1985, 107, 2662

21. Alizadeh, M. H.: Kemanil, T.; Tayebee, R. Monatsh. Chem. 2007, 138, 165.

22. Alizadeh, M. H.; Tayebee, R. Montsh. Chem. 2006, 137, 1063.

23. Tayebee, R, Rafiee, E. Bull. Chent. Soc. Ethiop. 2006, $20(2), 1$.

24. Tayebee, R.; Mahdavi, B. Asian Jomnal of Chemism, 2009, 21, 1565.

25. Tayebee, R.: Alizadeh, M. H. Cur. Sci. 2007,93, 133.

26. Tayebee, R.; Alizadeh, M. H. Chin. J. Chent 2007, 25, 1031.

27. Tayebee, R. Alizadeh, M. H. Wonatsh. Chem. 2007, 138.763.

28. Green, T. W.: Wuts, P. G. M. In Protective Groups in Organic Synthesis, 3rd ed, Wiley-Interscience, New York: 1999.

29. Altiokka, M. R.; Citak, A. Appl. Catal. A: Gen. 2003, 239, 141.

30. Chen, X.: Xu, Z: Okuhara, T. Appl Catal .1: Gen. 1999, 180 , 261 .

31. Liu, W. T; Tan, C. S. Liquid-Phase Ind. Eng. Chem. Res. 2001 , 40,3281 .

32. Yadav, G. D.; Thathagar, M. B.; React. Funct. Potym. 2002, 52 , 99.

33. Hoek, I.; Nijhuis, T. A.: Stankiewicz, A. I.: Moulịin, J. A. Appl. Catal. A: Gen. 2004, 266, 109.

34. Kirumakki, S. R.; Nagaraju, N.; Narayanan, S. Appl. Catol. A: Gen. 2004, 273, 1

35. Hiyoshi, M.: Lee, B.: Lu, D.: Hara, M.: Kondo, J. N.; Domen, K. Catal. Lett. 2004, 98, 181

36. Iizuka, T.; Fujie, S.; Ushikubo, T.; Chen, Z. H.; Tanabe, K. Appl. Catal. 1986, 28, 1 .

37. Okun, N. M.: Anderson, T. M.; Hill, C. L. J. Am. Chem, Soc. $2003,125,3194$

38. ten Brink, G. T.; Arends, I. W. C. E:; Sheldon, R. A. Science $2000,258,1636$

39. ten Brink, G. I.: Arends, I. W. C. E.; Sheldon, R. A. Adv. Synth. Catal. 2002, 34t, 355

40. North, E. O. Inorg. Symth. 1993, 1, 129.

41. Wu, H. J. Bial Chent. $1920,43,189$

42. Brevard, C.: Schimpf, R.: Toume, G.: Toume, C. M. J. Am. Chem. Soc. 1983, 105, 7059.

43. CRC, Handbook of Tables for Organic Contpond Identification, 3rd and 54th ed. 